\title{
BUILDING STUDENT ENGAGEMENT IN TEACHING AND LEARNING: AREAS FOR ENHANCEMENT
}

\author{
Alex Krouglov \\ London Metropolitan University, United Kingdom
}

\begin{abstract}
The paper analyses the engagement of students and teachers in developing a community of practice and the role of the institution in the process. Our research is based on surveys of students and teachers conducted in 2016 as part of the EU-funded Erasmus+ research project Internationalisation and Modernisation of Education and Processes in the Higher Education of Uzbekistan (IMEP). The questionnaires, developed by the project team of researchers, aimed to identify the areas of successful student engagement and where students did not engage actively in teaching, learning and other university and extracurricular activities. Our surveys of students and teachers provided us with the necessary information in order to establish the reasons for successful and less pro-active engagement of students. The results of the surveys also showed some differences in the level of engagement of teachers and students in the process of teaching and learning and how both groups viewed their involvement and the role of the institution. Two case studies presented by students selected for this project showcase their positive experience and confirm the results of our study. While the article deals with concrete data collected and analysed as part of the research, it addresses wider issues of student engagement, the provision of feedback and analyses the role of the main players in the process of teaching and learning enhancement.
\end{abstract}

Keywords: student engagement, Student Academic Representative (StAR), provision of feedback, enhancement of teaching and learning.

\section{Introduction}

Student engagement in the Higher Education has been central in the research of many scholars (Astin, 1993; Bryson, 2014; Fredricks et al., 2004; Gibbs, 2014; Kahu, 2013; Nygaard et al., 2013; Pascarella \& Ternzini, 2005). The term 'student engagement' is often substituted by other two seemingly close synonyms: 'involvement' and 'participation'. However, the term 'engagement' semantically incorporates more; on top of activity it requires feelings and sense-making (Harper \& Quaye, 2009: 5). The analysis of various definitions of the wideranging term 'student engagement' and how various authors approached it was provided by Trowler (2010). Apart from defining this multifaceted term, she aims to establish why we need student engagement, who benefits from it and what are critical success factors. Harrington et al. (2016) offer further development and 
rethinking of the term as a "process that enables students to experience this more collaborative, complex and nuanced version of education, which at its heart is about engagement as learning, and learning as becoming" (107).

Many authors agree that this is a complex process where a variety of factors and circumstances may have an impact on the way students engage in teaching and learning, university life, employers, professional organisations and wider community (Bryson, 2014; Kahu, 2013). However complex the process of engagement may be, the behaviours of students and teaching staff and their diversity play crucial part in the way they all engage and interact in teaching and learning (Harrington et al., 2016).

HE institutions play a key role in the creation of environment and building a culture which would encourage students to engage with all actors in the process of teaching and learning and achieve success (Coates, 2005; Kuh, 2007; Harrington et al., 2016). The role of institutions has become even greater in view of considerable shifts in the UK HE funding policy. Student engagement is usually defined and communicated via relevant policies in the Quality Manual, the Student Charter, the university mission or strategic plan. These documents set out institutional responsibilities to provide a suitable learning environment and a comprehensive range of support services for its students, and to involve students in decision making processes. It is worth mentioning that some UK institutions even developed more specific student engagement strategies, e.g. Student Engagement Strategy 2015-19 at Leeds Trinity University (http://www.leedstrinity.ac.uk/Key\%20Documents/Student\%20Engagement\%20 Strategy.pdf). It is therefore, one of the goals of our IMEP Project has been to identify the role of universities in encouraging and facilitating student engagement and propose guidance to HE institutions across Uzbekistan.

The engagement of major players and their motivation and attitudes were central in our research which aims to establish how students and academic staff view their engagement in teaching and learning, university activities and wider community, and what role the institution plays in this process, how it supports the main actors and emphasises the importance of various activities.

The above mentioned factors, the changing environment of the Higher Education and the need to assess the current level of student engagement led us to undertake this research and enabled us to formulate the main objectives. Apart from establishing how the major players view the role of the institution, the research also addresses the issues related to the provision of feedback by students and teaching staff and whether their feedback triggers any changes. It specifically aims to consider the frequency of feedback and topics covered. The analysed data will enable us to identify whether there is reliable interaction between major actors in the process of teaching and learning and how HE institutions and academic staff can enhance the culture of student engagement. 


\section{Methods}

\section{Participants}

A total of 144 university students and 33 teachers volunteered to participate in this study. Most students were female $-75 \%$. They studied at the following levels of study: Bachelor degree (junior year) - $41 \%$, Bachelor degree (senior year) $-36.1 \%$, Master degree $-16 \%$, and those who already graduated represented $6.9 \%$. The students involved in the study represented all age groups from 18 years to over 50 years old. The students spread more or less equally across all age groups which reflected the diversity of students at London Metropolitan University. The student group of $20-30$ years old was the largest group in our study $-43.9 \%$ while the rest of students were equally spread between 30-40 and 40-50 groups respondents. Students representing a variety of subjects taught at the university participated in the survey: Business, Health, Psychology, Applied Languages, Education, International Relations, Youth Work, and Criminology. However, the majority of students were from Social Sciences and Social Professions.

33 teachers were involved in the survey from Business \& Management, Art \& Architecture, Social Sciences and Social Professions, Applied Languages, Media and Communications. They had various teaching experience from 1 to 28 years, however the biggest groups were with experience of 5 years $-15.2 \%$ and 25 years - also $15.2 \% .66 .6 \%$ of participants were female teachers.

\section{Questionnaires}

Questionnaires for students and academic staff were developed by a group of researchers as part of Erasmus+ IMEP Project with an aim to contribute to the internationalisation and further enhancement of Quality Assurance System in the Higher Education of Uzbekistan through the development of continuous professional development, student and employer engagement in teaching and learning.

The questionnaires consisted of three parts: introduction, questions on employer engagement and student engagement, and were designed to assess how well students were prepared for their future careers and how actively they were involved in the life of their university. The information provided by students and academic staff will be compared with other partner universities in Greece, Latvia and Uzbekistan at the next stage of the Project and will assist in the development of guidelines for employer and student engagement. This paper, however, only considers the results of student and academic staff surveys at London Metropolitan University.

The Questionnaire for students addresses the issues of institutional role in supporting student engagement in various aspects of university life, how often and by what means students provide feedback, what areas they cover, whether they 
see any changes after the feedback is given, and in what activities students are involved during their academic year. In total, there were 7 groups of questions.

The Questionnaire for academic staff in a way mirrored the questions addressed to students and asked about the institution supporting various activities related to student engagement, how often and the way the feedback is provided, what areas are covered in the feedback and whether members of academic staff see any changes after the feedback is given.

In a nutshell, our research aimed to analyse how HE institutions support student engagement, whether students and academic staff are given opportunities for the provision of feedback and whether the provided feedback leads to any changes. In addition, we explored the issues of student and staff engagement in university life and wider community.

\section{Procedure}

Recruitment of participants was carried out by academic staff involved in the IMEP Project. Each participant agreed on an informed consent stating that the participation was voluntary, that individual answers will be reviewed only by members of the research team directly involved in the project, that no personal information that could be used to identify the participants would be asked during the survey. Participants were also assured that the results of the survey will be presented only as an aggregated statistical analysis.

The results of the survey were analysed by two teams of researchers working on employability and student engagement. Since there was a combination of numerical data and comments from respondents, the research involved quantitative and qualitative data analysis. In order to clarify and confirm the results of the surveys two students were selected for the provision of case studies of good practice and their views on the issues of student engagement at the next stage of the research.

\section{Results and discussion}

The role of institutions and the HE system as a whole is central in creating the culture and environment of student and teacher active engagement in teaching and learning. This role is becoming even greater in view of the changing landscape in the Higher Education and the growing consumerist approaches when engaging with learning (Kandiko \& Mawer, 2013). These changes call for rethinking engagement types proposed by Pike and Kuh (2005) and developing new fit-for-purpose strategies.

Our research addressed the question as to how the institution empowers student engagement. As shown in Figure 1,80\% of students agreed that the university ensures that they take full responsibility for their learning. This empowerment of students is important for encouraging the use of a variety of 
methods and approaches in shaping the culture of student engagement thus enabling flexibility in view of student diversity. Lower figures in the other two questions about developing a sense of belonging and encouraging students to make active decisions about how you study as well as the answers to questions about being part of the community may require some enhancement procedures and actions at institutional level. However, the results of the survey may not be conclusive enough since many Bachelor degree students (junior year) participated in the survey who might not have had the time to engage either at the course or university level. Senior year and Master degree students showed higher results in their replies to questions in this part of the survey, thus clearly indicating a more pro-active engagement in most areas.

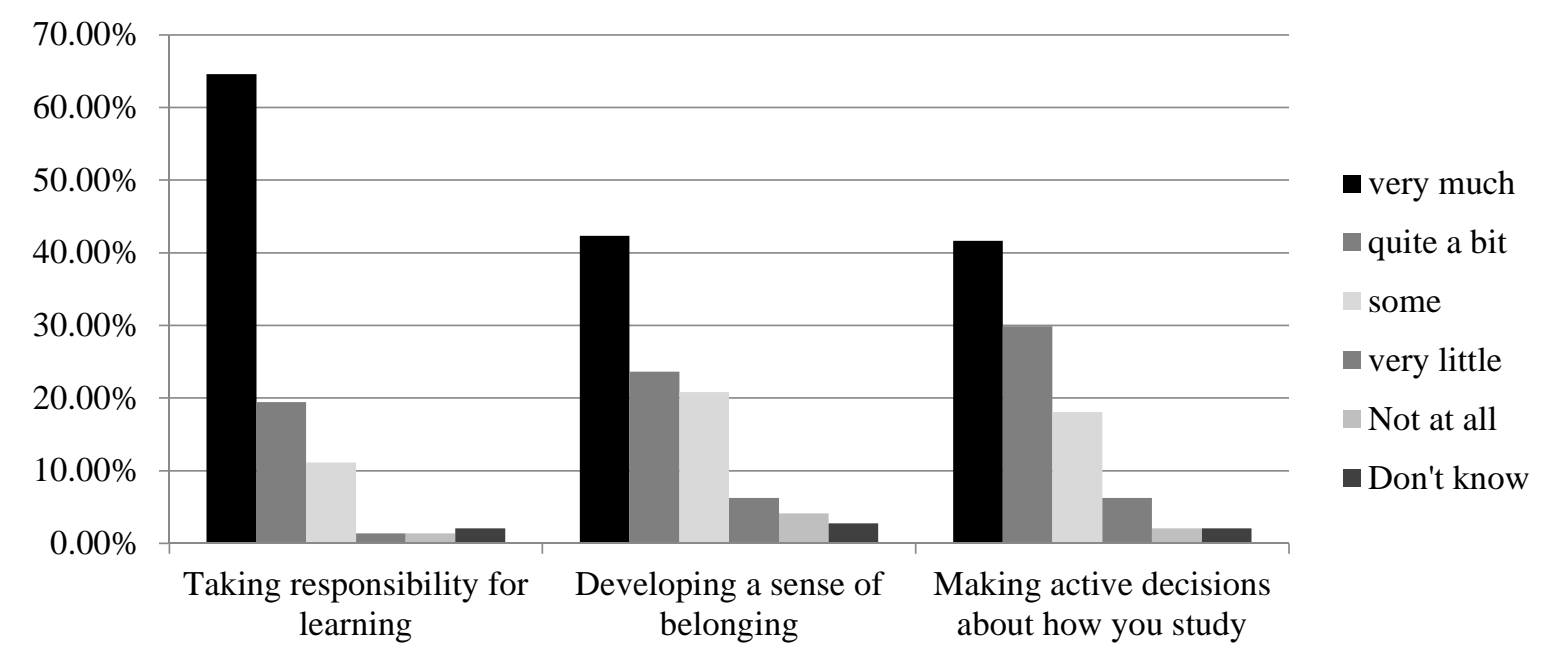

Figure 1 Students replies to the question "How much did your institution emphasise the following activities?"

The role of feedback has been identified as crucial in achieving teaching and learning goals and objectives. It is therefore, there are four questions targeting the issue of feedback to students and academic staff. The questions specifically address the frequency and the format of feedback, what aspects are usually covered in the feedback, and whether respondents see any changes after the feedback is provided. If $84.8 \%$ of academic staff replies show that they provide feedback twice or more per year, only $57.6 \%$ of students think they provide feedback twice a year or more regularly - see Figure 2. One of the reasons could be that many junior year Bachelor students participated in the survey who did not have an opportunity of providing feedback at the beginning of their course. Some of them provided additional explanations in their questionnaires that they had not had an opportunity of providing feedback yet. At the same time, it should be noted that $89.6 \%$ of students confirmed that they provided feedback at least once a year. 


\section{Frequency of feedback}

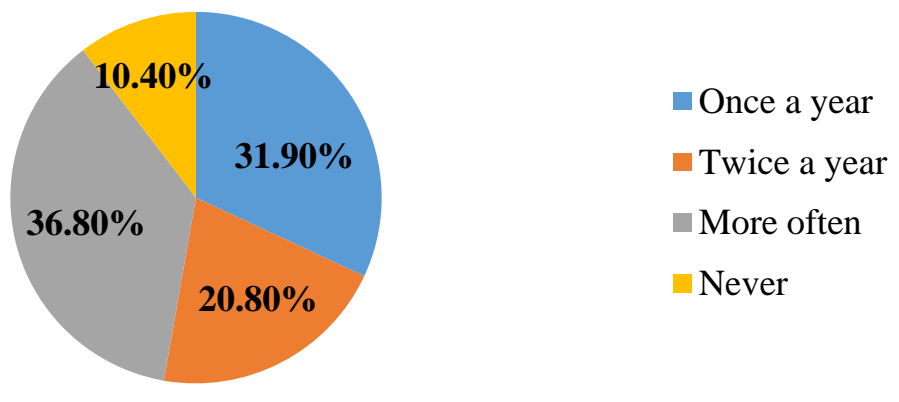

Figure 2 Student survey: How often are you asked to provide feedback during the academic year?

The results of our research showed that $72.9 \%$ of students specifically pointed out that they provided the feedback through questionnaires and over a third of student-respondents $(36.1 \%)$ mentioned feedback meetings through a group of representatives, while $12.5 \%$ provided feedback by writing to academic and administrative staff and $13.2 \%$ of respondents put 'other' in their replies see Figure 2 for more details. In marked contrast to students, $84.8 \%$ of academic staff provided feedback through the meetings and only $48.5 \%$ mentioned questionnaires. It looks that academic staff provide their feedback through more channels to both students and senior managers and administrators at the university. $42.4 \%$ of academic staff provided feedback in writing and $30.3 \%$ used other channels of communication. These findings show some inconsistencies especially since the selected students for our project specifically mentioned the importance of meetings with student representatives for providing comprehensive feedback on various issues related to their teaching and learning.

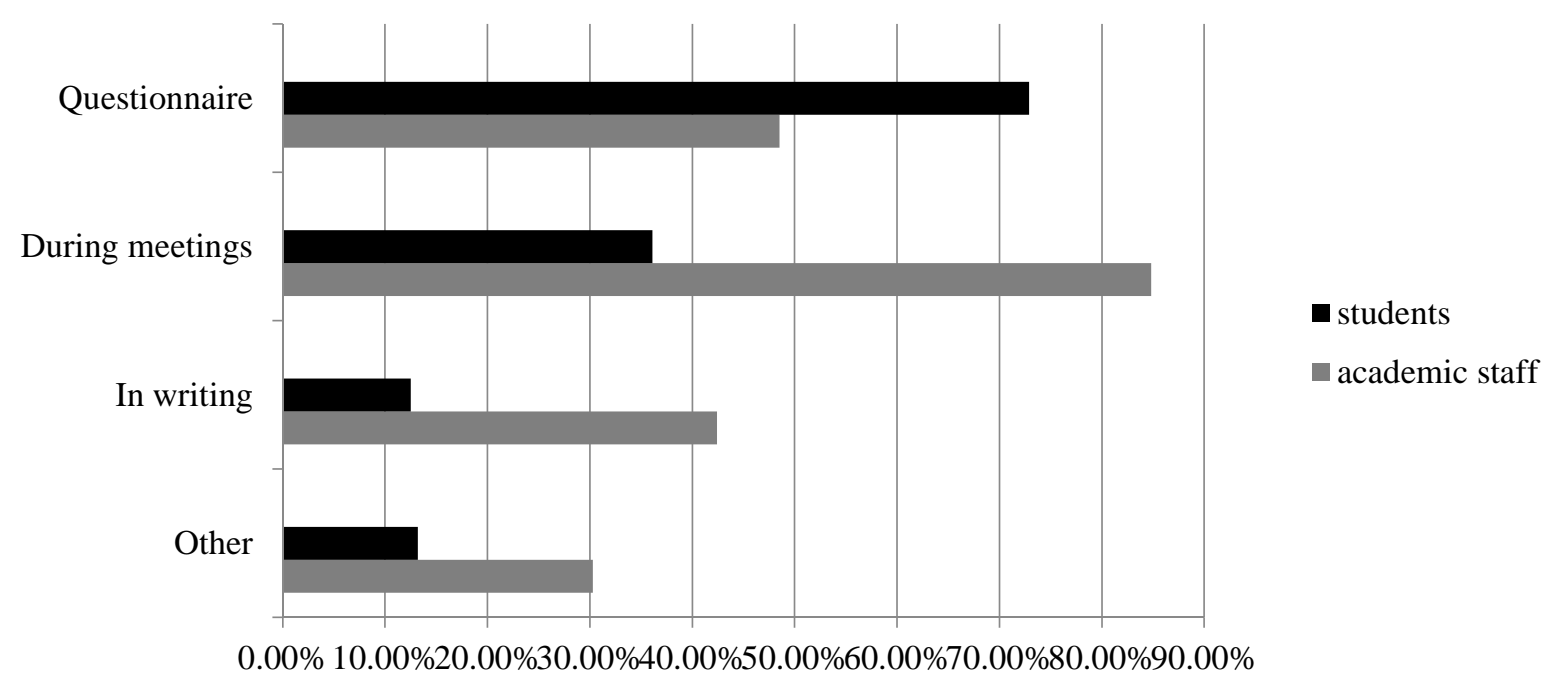

Figure 3 How the feedback is provided during the academic year? 
As shown in Figure 4, $72.9 \%$ of students identified teaching as the main topic in their feedback, other important issues included the following: assessment $(67.4 \%)$, facilities $(43.8 \%)$, administration $(42.4 \%)$, library $(35.4 \%)$ and IT $(28.5 \%)$. It is interesting that teaching $(96.9 \%)$ and assessment $(87.5 \%)$ made the major part of feedback given by the academic staff. However, our research acknowledges that administration is also important in the feedback provided by teachers $-75 \%$. Overall, academic staff provide more holistic feedback and tend to include other aspects which have an impact on teaching and learning: facilities $(68.8 \%)$, IT (62.5\%), library (56.3\%) due to their role in the process of teaching and learning.

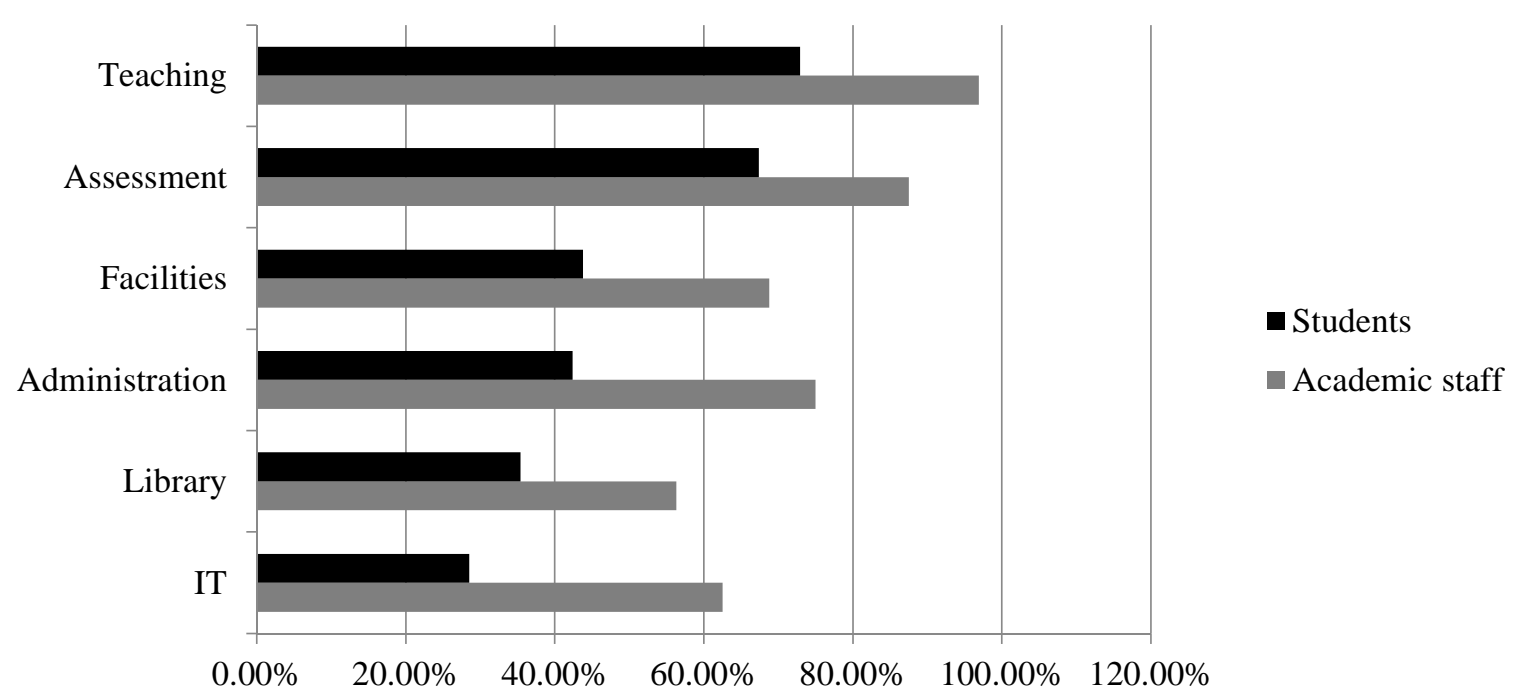

Figure 4 Aspects covered in feedback by students and academic staff

With regards to changes after the feedback was provided, $66.4 \%$ of students and $75.9 \%$ of staff replied that they saw changes. Somewhat lower figure for students can be explained by the number of junior students who participated in the survey and may not have had enough experience in university life.

In the last part of the questionnaires, students and academic staff were asked about their engagement in various university activities. Students were asked about developing a joint community of students and teachers, their contribution to course improvement and helping other students, involvement in other university activities, participation in extra-curricular and co-curricular activities, community-based projects, contribution or a presentation at an event. If academic staff showed active participation in almost all activities, students were more active in contributing to joint community of teachers and students (61 respondents) and helping other students (55 respondents) - see Figure 5 for more details. 


\section{Students}

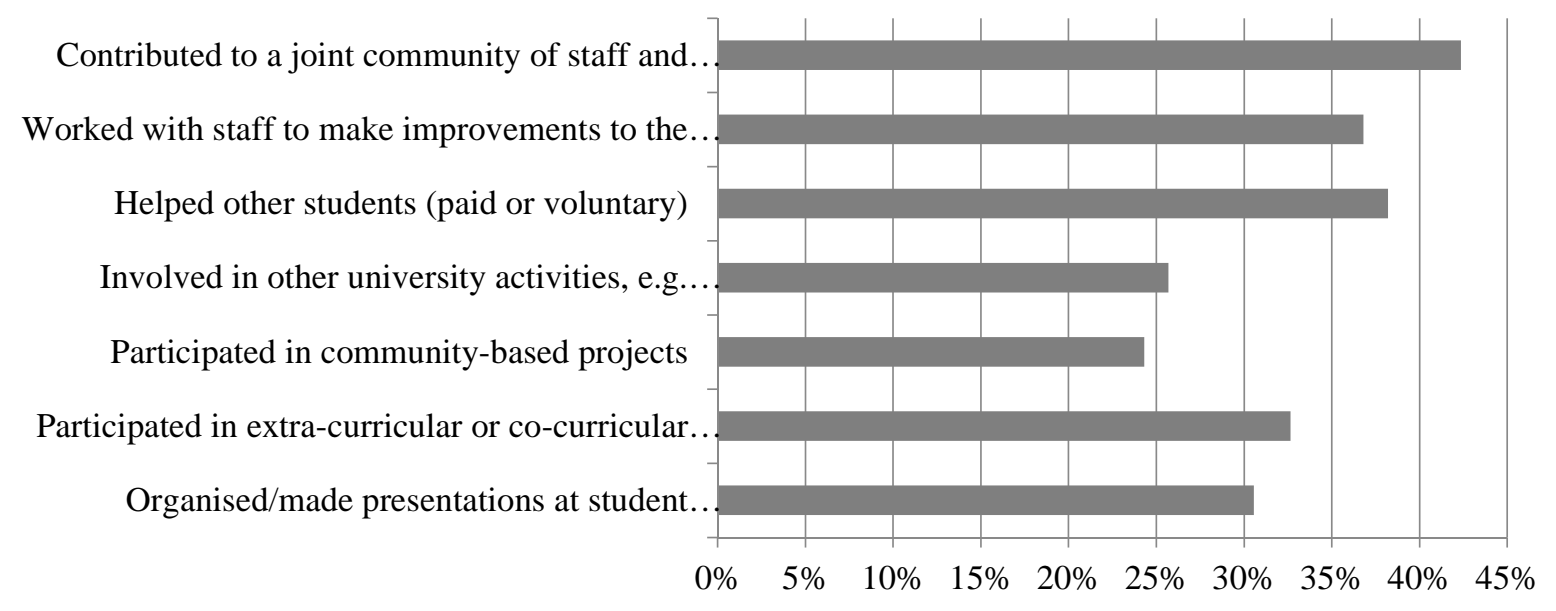

Figure 5 Involvement of students in various activities at the university

Survey results showed that there is room for enhancement in some areas directly or indirectly linked to student engagement. Students could involve more actively in community-based projects and numerous university activities which would enhance their learning and ensure better understanding of a wider context.

\section{Feedback from selected students}

As part of our IMEP Project and in order to support our findings based on the analysis of surveys, two students were selected and asked to present two case studies showcasing positive experience of student engagement at the university. In consultations with their peers they produced two case studies of good practice in student engagement.

One of their case studies covered the system of Student Academic Representatives (StARs). Students on each course elect their StAR who makes a difference to the lives of London Metropolitan University students by raising issues around specific course-related areas such as tutor feedback, IT issues, accommodation, library resources or anything else which may have an impact on teaching and learning. Each StAR is responsible for gathering the views of their classmates, identifying and formulating the main issues and presenting them to the course team or course committee at the university which consists of academic staff involved in the teaching the course, IT and Library representatives. StARs present issues on behalf of all students and together with the academic staff and other colleagues discuss possible ways to rectify the current situation. They report back to classmates about the decisions of the course team/committee, share information and work closely with the course leader. This is an opportunity to 
work closely with staff, university management, the Students' Union and the National Union of Students (NUS).

Another case study of good practice dealt with the participation in the Student Council which is the main representative body of the Students' Union. It is made up of around 89 students who represent a number of constituencies from across the university. The Student Council is there to discuss and debate issues which are of interest or concerns to students. It can raise its concerns to and be consulted by the university.

It is important to note that these case studies illustrated our data gathered during the survey. They showed that these activities offer further development of skills which enhance their learning and further employment opportunities. Among the skills they developed, students particularly stressed the importance of communication, interpersonal, teamwork skills which "will benefit students in transformative and sustainable ways" (Harrington et al., 2016: 115). Active involvement in these activities provides them with valuable experience for their learning and future employment.

\section{Conclusions}

Our research analysed only some factors or rather actors in creating the culture of student engagement. The analysis of the data confirmed Trowler's argument that "it does not happen by magic" but requires certain prerequisites which ensure active engagement in teaching and learning (2010: 36). Institutions, academic staff and students need to work closely together in order to create the fertile ground for students to engage and maximise the effectiveness of teaching and learning.

One of the main findings of this research is that both students and teachers responded positively to the work of the institution to enhance communication and engage actively in teaching and learning. Both groups were actively involved in the provision of feedback to each other on a number of issues, while teaching and assessment were identified as the main topics in the surveys conducted by us.

The research confirms that the university sufficiently emphasises the importance of students' responsibility for their learning, however our data also shows that there is a scope for enhancement in certain aspects of shaping the community of staff and students and creating the atmosphere of being part of the community. The idea of creating an inclusive environment for engagement with teaching and learning was developed by scholars in the field of education (Kuh, 2005; Markwell, 2007), and students would like to see more active involvement. The university has to enhance the environment, relevant strategies and offer new opportunities in the changing landscape of the Higher Education in the UK. Even 
small enhancement will make a big difference to all parties involved in the process of teaching and learning.

Our survey showed that students engage with feedback and understand its importance for continuous enhancement of their teaching and learning. 89.6\% of student respondents provided feedback at least once during the academic year. This figure could be even higher provided the survey covered only Master degree and Bachelor degree senior students. While the majority of student-respondents provided feedback through questionnaires and during meetings, academic staff respondents pointed out that the feedback was mostly given during the meetings over $80 \%$. Both academic staff and students consider that teaching and assessment constitute key areas of feedback.

The analysis of the surveys and the case studies prepared by selected students show that the feedback channelled via StARs is effective, especially since student representatives have an opportunity to discuss issues with staff and establish ways for improvement during course committee meetings. This approach empowers students and enables them to contribute to the continuous enhancement of teaching and learning and engage creatively in various activities together with academic staff and colleagues working across the university.

\section{References}

Astin, A. W. (1993). What Matters in College? Four Critical Years Revisited. San Francisco: Jossey-Bass.

Bryson, C. (ed.) (2014). Understanding and Developing Student Engagement. Abingdon, Routledge.

Coates, H. (2005). The Value of Student Engagement for Higher Education Quality Assurance. Quality in Higher Education. II (I), pp. 25-36.

Fredricks, J. A., Blumenfield, P. C., \& Paris, A. H. (2004). School Engagement: Potential of the Concept, State of the Evidence. Review of Educational Research. 74 (I), pp. 59-109.

Gibbs, G. (2014). Student engagement, the latest buzzword. Times Higher Education (online). Available at https://www.timeshighereducation.com/news/student-engagement-thelatest-buzzword/2012947.article (accessed 14.02.17)

Harper, S. R., \& Quaye, S. J. (2009). Beyond Sameness, with Engagement and Outcomes for All. In S. R. Harper, \& S. J. Quaye (eds.), Student Engagement in Higher Education. New York and London: Routledge, pp. 1-15.

Harrington, K., Sinfield, S., \& Burns, T. (2016). Student Engagement. In Pokorny, H. \& Warren, D. (eds) Enhacing Teaching Practice in Higher Education. London: Sage.

Kahu, E. R. (2013). Framing student engagement in higher education.Studies in Higher Education, 38 (5): 758-73.

Kandiko, C. B., \& Mawer, M. (2013). Student Expectations and Perceptions of Higher Education: Final Report. London: King's Learning Institute.

Kuh, G. D. (2007). How to Help Students Achieve. Chronicle of Higher Education. 53 (41), pp. B 12-13. 
Proceedings of the International Scientific Conference. Volume I, May $26^{\text {th }}-27^{\text {th }}$, 2017. 238-248

Markwell, D. (2007). The Challenge of Student Engagement. Keynote address at the Teaching and Learning Forum. University of Western Australia, 30-31 January.

Nygaard, C., Brand, S., Bartholomew, P., \& Millard, L. (eds) (2013). Student Engagement: Identity, motivation and community. Faringdon: Libri.

Pascarella, E. T., \& Ternzini, P. T. (2005). How College Affects Students: A Third Decade of Research. San Francisco: Jossey-Bass.

Pike, G. R., \& Kuh, G. D. (2005). A Typology of Student Engagement for American Colleges and Universities. Research in Higher Education. 46 (2), pp. 185-209.

Trowler, V. (2010). Student Engagement Literature Review. York: HEA. Available at https://www.heacademy.ac.uk/resources/detail/evidencenet/Student_engagement_literat ure_review (accessed 4.02.17) 